\title{
Anesthesia for Cesarean Delivery in a Low-Resource Setting, an Initial Review
}

\author{
Elizabeth Ogboli-Nwasor*, Abdulghaffar Adeniyi Yunus \\ Department of Anaesthesia, Ahmadu Bello University Teaching Hospital, Zaria, Nigeria \\ Email: ${ }^{\text {drnwasor@yahoo.com }}$
}

Received 3 July 2014; revised 12 August 2014; accepted 4 September 2014

Copyright (C) 2014 by authors and Scientific Research Publishing Inc.

This work is licensed under the Creative Commons Attribution International License (CC BY). http://creativecommons.org/licenses/by/4.0/

c. (i) Open Access

\begin{abstract}
Background: Bearing in mind the recent advances in obstetric anesthesia, the safety of both mother and child is of paramount importance, especially in a setting where resources are limited. We set out to find the pattern of cases presenting for cesarean delivery and the types of anesthesias provided for the management of these patients. Methods: A retrospective survey was conducted involving all anesthetics provided for cesarean delivery from January 2006 to December 2009 in Ahmadu Bello University Teaching Hospital, Zaria, Nigeria. Information such as age, indications and anesthetic technique, including drugs used, were extracted from patients' records. Data were subjected to statistical analysis using Statistical Package for Social Sciences (SPSS) version 17.0. Results: There were a total of 577 anaesthetics conducted for cesarean delivery during the period under review out of 4277 live births, giving a cesarean delivery rate of $13.5 \%$. General anesthesia (GA) was administered on $266(46 \%)$ of these patients, while $279(48 \%)$ cases were done under subarachnoid block(SAB). $16(3 \%)$ patients had combined GA and SAB, while $16(3 \%)$ patients received epidural anesthesia. There were 302 emergency cesarean deliveries out of 577 cases, giving an emergency cesarean delivery rate of $52 \%$. The commonest indication for cesarean delivery was two previous cesarean deliveries. Conclusion: A large percentage of our obstetric cases are being done under general anesthesia. Though majority of the conducted regional anesthesia were spinals (SAB), only a few cases were done under epidural block. Subspecialty training of anesthetists will go a long way to improve the current trends.
\end{abstract}

\section{Keywords}

Anesthesia, Cesarean Delivery, Epidural, Low-Resource, Sub-Arachnoid Block

"Corresponding author. 


\section{Introduction}

Caesarean section is the delivery of the fetus, placenta and membranes after the age of viability through an abdominal and uterine incision [1]. The incidence of caesarean section varies widely globally, ranging from $5 \%$ to $25 \%$ with a continued rise in developed countries, while in most developing countries the rate is still relatively low [1] [2]. In Nigeria, the rate of caesarean section varies from one center to the other with 10.3\% in Enugu [3], 10.5\% (Makurdi) [4], 11.4\% (Zaria) [5], 15.8\% (Jos) [6] and 20.3\% in Birnin-Kebbi [7]. At the time of this review, we found a cesarean delivery rate of $13.5 \%$, which is lower than the current cesarean delivery rate in our center (Zaria) which is $23 \%$ [8].

The Ahmadu Bello University Teaching Hospital (ABUTH) Zaria is a 500 bed tertiary referral hospital which serves most of northern Nigeria, especially Kaduna, Kano, Katsina, Jigawa and Zamfara state, and also receives patients from the neighboring Niger Republic. The increase in caesarean section rates is largely driven by several factors which include societal demands for improved fetal outcome, protection of pelvic floor and the aspiration of obstetricians to meet these demands [9].

The anesthetic management of a pregnant patient is more challenging than their non-pregnant counterparts for many reasons, including the physiological changes associated with pregnancy. Pregnancy is considered "highrisk" when it is accompanied by any condition that is unfavorable to the mother, fetus or both [10]. The challenges presented by a parturient, requiring anesthesia or analgesia, or both, make the role of the obstetric anesthesiologist both challenging and rewarding [11].

Nigeria belongs to the lower-middle-income group of countries with a GDP of \$2760 (\$1026 to \$4035). Lowand middle-income economies are sometimes referred to as developing economies and the resources are usually limited because of the development needs [12].

The peculiarities of providing safe anesthesias in regions where resources are limited or scarce can be quite daunting. We studied the pattern of cases presenting for cesarean delivery and the types of anesthesia provided for the management of these patients in our center.

\section{Methods}

The study was a retrospective survey of all anesthetics provided for cesarean delivery in Ahmadu Bello University Teaching Hospital, Zaria, Nigeria, from January 2006 to December 2009. Patient's records were reviewed and information such as age, indications and anesthetic technique including drugs used were extracted from patients' records. We classified the degree of urgency of cesarean section using the traditional terms "elective" and "emergency". Data was subjected to statistical analysis using SPSS version 17.0. The data is presented in relevant tables and tests of significance (chi-square test) were conducted where relevant.

\section{Results}

The age range was from 18 to 47 years although age was not specified in 55 patients (9.5\%). The age distribution is shown in Table 1. Diabetes Mellitus in pregnancy was commoner in the 35 - 39 year olds as shown in

\begin{tabular}{|ccc|}
\hline Table 1. Age. & Number & $\%$ \\
\hline Age & 23 & 4.0 \\
\hline $15-19$ & 87 & 15.1 \\
$20-24$ & 171 & 29.6 \\
$25-29$ & 145 & 25.2 \\
$30-34$ & 78 & 13.5 \\
$35-39$ & 15 & 2.6 \\
$40-44$ & 3 & 0.5 \\
Above 44 & 55 & 9.5 \\
Unrecorded & 577 & 100 \\
Total & & \\
\hline
\end{tabular}


Table 2. The indications for cesarean delivery included previous section, abnormal lie, pregnancy induced hypertension and diabetes mellitus in pregnancy, but commonest indication for cesarean delivery was two previous cesarean delivery, see Table 3. Forty-six percent (46\%) of the patients received general anaesthesia (GA), while forty-eight percent $(48 \%)$ were done under subarachnoid block (SAB), and three percent (3\%) patients had combined GA and SAB, while another three percent (3\%) patients had epidural anesthesia. The poor recording of information is a major drawback for this study.

\section{Discussion}

Cesarean delivery rate is rising worldwide and Nigeria is no exception. The trends show higher cesarean delivery rates in the south where Igberase et al reported a cesarean delivery rate of 34.\% (Eku, Delta State) while Ojiyi and colleagues reported a rate of 33.2\% (Orlu, Imo State) [13] [14].

The cesarean birth rate in the United States is now approximately 30\% of all live births [15]. In our review the cesarean delivery rate was $13.5 \%$ which is lower than the current cesarean delivery rate in our center (Zaria) which is $23 \%$ [8]. Increased use of the procedure has been attributed to the liberalization of indications for fetal "distress" as well as elective repeat cesarean delivery [16]. According to the literature, the most common indications for cesarean delivery include "failure to progress," non-reassuring fetal status, cephalo-pelvic disproportion, malpresentation, prematurity, and previous uterine surgery [11]. In our review, the most common indication for cesarean delivery was "two previous cesarean deliveries" and this group also recorded the second highest number of SAB. See Table 1.

The choice of anesthesia for cesarean delivery depends on the indications for the surgery, the degree of urgency, maternal status, and desires of the patient [11]. Most patients undergoing cesarean delivery in the United States do so under spinal or epidural anesthesia [17]. In our review, forty-six percent (46\%) of the patients re-

Table 2. Age against diagnosis/indication for surgery.

\begin{tabular}{|c|c|c|c|c|c|c|c|}
\hline Age & $\begin{array}{c}\text { Two previous } \\
\text { Caesarean Delivery }\end{array}$ & Abnormal Life & $\begin{array}{l}\text { Diabetes } \\
\text { Mellitus }\end{array}$ & Placenta Previa & $\begin{array}{l}\text { Preeclampsia/ } \\
\text { Eclampsia }\end{array}$ & Others & Total \\
\hline $15-19$ & 6 & 6 & - & - & 5 & 10 & 27 \\
\hline $20-24$ & 14 & 13 & 5 & 6 & 7 & 27 & 72 \\
\hline $25-29$ & 46 & 14 & 6 & 7 & 6 & 74 & 153 \\
\hline $30-34$ & 51 & 13 & 11 & 9 & 8 & 34 & 126 \\
\hline $35-39$ & 39 & 10 & 12 & 5 & 6 & 20 & 92 \\
\hline $40-44$ & 9 & 6 & 5 & - & - & 18 & 38 \\
\hline Above 44 & 5 & - & - & - & - & 5 & 10 \\
\hline Unrecorded & 27 & 5 & 5 & - & 8 & 14 & 59 \\
\hline Total & 197 & 67 & 44 & 27 & 40 & 202 & 577 \\
\hline$\%$ & 34.1 & 11.7 & 7.7 & 4.6 & 6.9 & 35 & 100 \\
\hline
\end{tabular}

Table 3. Indications for cesarean delivery by anaesthetic technique.

\begin{tabular}{|c|c|c|c|c|c|c|c|c|}
\hline \multirow[b]{2}{*}{$\begin{array}{l}\text { Anaesthetic } \\
\text { Techniques }\end{array}$} & \multicolumn{7}{|c|}{ Indications } & \multirow[b]{2}{*}{ Total } \\
\hline & $\begin{array}{c}\text { Previous } \\
\text { Caesarean } \\
\text { Delivery }\end{array}$ & $\begin{array}{l}\text { Abnormal } \\
\text { Lie }\end{array}$ & $\begin{array}{l}\text { Diabetes } \\
\text { Mellitus }\end{array}$ & $\begin{array}{l}\text { Placenta } \\
\text { Previa }\end{array}$ & $\begin{array}{l}\text { Preeclampsia/ } \\
\text { Eclampsia }\end{array}$ & $\begin{array}{c}\text { Fetal } \\
\text { Distress }\end{array}$ & $\begin{array}{c}\text { Not } \\
\text { Specified }\end{array}$ & \\
\hline G A & - & - & - & - & - & 19 & 7 & 26 \\
\hline $\begin{array}{c}\text { GA + Endotracheal } \\
\text { tube }\end{array}$ & 81 & 22 & 10 & 10 & 18 & 89 & 10 & 240 \\
\hline $\mathrm{GA}+\mathrm{SAB}$ & 3 & - & - & - & - & 8 & 5 & 16 \\
\hline SAB Only & 102 & 31 & 19 & 5 & 13 & 97 & 12 & 279 \\
\hline Epidural Block & 2 & - & - & - & - & 8 & 6 & 16 \\
\hline Total & 188 & 53 & 29 & 15 & 31 & 221 & 40 & 577 \\
\hline
\end{tabular}


ceived general anesthesia (GA), while forty-eight percent (48\%) were done under subarachnoid block (SAB), and three percent (3\%) patients had combined GA and SAB, while another three percent (3\%) patients had epidural anesthesia. One of the reasons why there are fewer epidurals is that the epidural packs and combined spinal and epidural packs are more expensive than spinal needles.

In modern anaesthesia practice, regional techniques are preferred to general anaesthesia for many types of surgery, particularly in obstetric care. Improved outcomes have been recorded in UK practice, but the techniques remain under utilized in many parts of the world [18]. In our review, we found that even though the majority of patients $54 \%$ had regional anaesthesia, there is still large number of cases of cesarean delivery being done under general anaesthesia (48\%). In a Cochrane review by Afolabi et al. [19], they found no evidence to show that regional anaesthesia is superior to general anaesthesia in terms of major maternal or neonatal outcomes. They recommended that further research to evaluate neonatal morbidity and maternal outcomes that satisfaction with the technique, be conducted [19].

In a study by Eshiet et al. in Calabar, South Eastern Nigeria [20], general anaesthesia was employed in 555 (60.3\%) while spinal was used in 365 (39.7\%), which showed higher incidence of GA than spinal. Our findings show that regional anaesthesia especially SAB is becoming even more frequently used in Nigeria for cesarean delivery than earlier reports. This is reflected in the findings by Okafor et al. [21] in Enugu, Eastern Nigeria, who conducted a retrospective survey of hospital records of cesarean deliveries over a 4-year period from January 2003 to December 2006. There were 2968 deliveries and 3140 births (2959 live births), with 729 women (24\%) delivered by cesarean delivery. There was a yearly increase in the use of regional anaesthesia from 18\% in 2003 to $48 \%$ in 2004 and $72.6 \%$ in 2005, but it fell to $71 \%$ in 2006 [21].

Eshiet et al. opined that spinal anaesthesia when there is no contra indication is recommended for safe obstetric anaesthesia. Brisk pre-operative evaluation, optimization of pre-operative clinical status of parturients and competent anaesthetist are of paramount importance. Although epidural, spinal, continuous spinal, and combined spinal and epidural anaesthesia techniques (CSE) have all been advocated, most straightforward cesarean delivery are now performed with single-shot spinal anesthesia, which has been found to be faster, provides a superior block, and is more cost effective, especially as compared with epidural anesthesia [22].

Spinal (subarachnoid) anesthesia offers many advantages for cesarean delivery. It has a very rapid onset and provides a dense neural block. Because of the small doses used, there is little risk of local anesthetic toxicity and minimal transfer of drug to the fetus. In addition, failures (including incomplete or patchy blocks) are very infrequent with spinal anesthesia. Disadvantages of this technique include the finite duration of anesthesia and a higher incidence of hypotension [11].

In the study by Eshiet [20], the outcome of obstetric anaesthesia following emergency cesarean delivery showed an emergency cesarean delivery rate of $60 \%$. This is comparable to the findings of our study, which had an emergency cesarean delivery rate of $52 \%$ which is also comparable with similar studies in Nigeria [21]. In that study by Eshiet et al. the main indications for the emergency cesarean delivery were obstructed labours, unlike the findings in our review, where the main indication was previous cesarean delivery.

However, a prospective study of 196 patients by Desalu and Afolabi in South Western Nigeria, showed contrasting findings [23]. In their series, elective surgery was performed for $17.3 \%$, while $47.4 \%$ and $28.6 \%$ had urgent and emergency cesarean delivery respectively. Urgency of surgery was not documented in $6.7 \%$ of cases. Previous cesarean delivery was the commonest indication for elective procedures (47\%), foetal distress for emergency (62.5\%) and previous cesarean delivery in labour for urgent procedures (30.1\%). The study by Desalu et al. [23] showed that general anaesthesia was employed in $33.2 \%$ of patients while regional anaesthesia was used in 66.8\%. This is very similar to trends seen by Okafor et al. [21]. Fifty per cent of emergency cases had general anaesthesia. Regional anaesthesia was used in $72 \%$ of urgent and $85.3 \%$ of elective procedures. The commonest regional technique was spinal anaesthesia (60.7\%). Desalu et al. [23] concluded that the choice of anaesthesia depends on the urgency of surgery and the medical condition of the mother and that general anaesthesia was more likely to be administered for bleeding emergencies and foetal distress, while spinal anaesthesia was preferred for elective and urgent cases or when maternal disease existed.

\section{Limitations}

Due to poor record keeping practices and the retrospective nature of the survey, our records were incomplete in some cases. For this reason also we did not study morbidity and mortality pattern and fetal outcome with refer- 
ence to general versus regional anaesthesia. This is an initial survey and there is need to strengthen our record keeping facilities and conduct more studies in these areas that have not been covered in this survey.

\section{Conclusion}

In spite of the fact that general anaesthesia was no longer popular in the western world for cesarean delivery, we found that a large percentage of cesarean deliveries at Ahmadu Bello University Teaching Hospital were done under general anesthesia during the review period from 2006-2009. The majority of regional anesthesia conducted was spinals (SAB), while only a few cases were done with epidural block. A follow-up review is needed to study the changing trends in obstetric anesthesia practice in this centre.

\section{References}

[1] Incerpi, M.H. (2007) Operative Delivery. In: Decherney, A.H., Nathan, L., Goodwin, T.M. and Laufer, N., Eds., Current Diagnosis and Treatment Obstetrics and Gynaecology, McGraw Hill, New York, 461-476.

[2] Jaiyesinmi, R.A. and Ojo, O. (2003) Caesarean Section. In: Okonofua, F. and Odunsi, K., Eds., Contemporary Obstetrics and Gynaecology for Developing Countries, Women's Health and Action Research Centre, Benin City, 592-621.

[3] Megafu, U. and Nweke, P.C. (1991) Maternal Mortality from Caesarean Section. Tropical Journal of Obstetrics and Gynaecology, 9, 1-4.

[4] Swende, T.Z., Agida, E.T. and Jogo, A.A. (2007) Elective Caesarean Section at the Federal Medical Centre Makurdi, North-Central Nigeria. Nigerian Medical Journal, 16, 372-374.

[5] Sule, S.T. and Matawal, B.I. (2003) Comparisons of Indications for Caesarean Section in Zaria, Nigeria: 1985 and 1995. Annals of African Medicine, 2, 77-79.

[6] Mutihir, J.T., Daru, P.H. and Ujah, I.O. (2005) Elective Caesarean Section at Jos University Teaching Hospital. Tropical Journal of Obstetrics and Gynaecology, 22, 39-41.

[7] Nwobodo, E.I. and Wara, H.L. (2004) High Caesarean Section Rate at Federal Medical Centre, Birnin-Kebbi: Real or Apparent? Nigerian Medical Practitioner, 46, 39-40. http://dx.doi.org/10.4314/nmp.v46i2.28724

[8] Department of Obstetrics and Gynaecology Statistics, Ahmadu Bello University Teaching Hospital. (2011) Unpublished Data.

[9] Shehu, D.J. (1992) Socio-Cultural Factors in the Causation of Maternal Morbidity and Mortality in Sokoto. In: Kisekka, M., Ed., Women’s Health Issues in Nigeria, Tamaza Publishing Company Limited, Zaria, 203-214.

[10] Korula, M. (2006) The High-Risk Obstetric Patient-Anaesthetic Implications. The Indian Anaesthetists Forum. Online ISSN 0973-0311. http://www.theiaforum.org/article/

[11] Birnbach, D.J. and Browne, I.M. (2009) Anesthesia for Obstetrics. In: Miller, R.D., Eriksson, L.I., Fleisher, L.A., Wiener-kronish, J.P. and Young, W.L., Eds., Miller's Anesthesia, 7th Edition, Churchill Livingstone, Edinburg, 22032210.

[12] http://data.worldbank.org/news/newest-country-classifications-released accessed 20/08/14

[13] Igberase, G.O., Ebeigbe, P.N. and Andrew, B.O. (2009) High Caesarean Section Rate: A Ten Year Experience in a Tertiary Hospital in the Niger Delta, Nigeria. Nigerian Journal of Clinical Practice, 12, 294-297.

[14] Ojiyi, E., Dike, E., Anolue, F. and Chukwulebe, A. (2012) Appraisal of Caesarean Section at the Imo State University Teaching Hospital, Orlu, Southeastern Nigeria. The Internet Journal of Gynecology and Obstetrics, 16, No. 2.

[15] Hamilton, B.E., Martin, J.A., Ventura, S.J., et al. (2005) Births: Preliminary Data for 2004. National Vital Statistics Reports, 54, 1-17.

[16] Depp, R. (1991) Cesarean Delivery and Other Surgical Procedures. In: Gabbe, S.G., Niebyl, J.R. and Simpson, J.L., Eds., Obstetrics: Normal and Problem Pregnancies, Churchill Livingstone, New York, 635.

[17] Braveman, F.R., Scavone, B.M., Wong, C.A. and Santos, A.C. (2009) Obstetrical Anesthesia. In: Barash, P.G., Cullen, B.F., Stoelting, R.K., Cahalan, M.K. and Stock, M.C., Eds., Clinical Anesthesia, Lippincott Williams \& Wilkins, Philadelphia, 1137-1170.

[18] Schnittger, T. (2007) Regional Anaesthesia in Developing Countries. Anaesthesia, 62, 44-47. http://dx.doi.org/10.1111/j.1365-2044.2007.05297.x

[19] Afolabi, B.B., Lesi, A.F.E. and Merah, N.A. (2006) Regional versus General Anaesthesia for Caesarean Section. Cochrane Database of Systematic Reviews, 10. http://dx.doi.org/10.1002/14651858.CD004350.pub2

[20] Eshiet, A.I., Udoma, E.J., Ekanem, A.D. and Dada, A. (2003) Effect of Anaesthesia on Morbidity and Mortality in Emergency Caesarean Section Patients in Calabar, Nigeria. Nigerian Journal of Physiological Sciences, 18, 77-81. 
[21] Okafor, U.V., Ezegwui, H.U. and Ekwazi, K. (2009) Trends of Different Forms of Anaesthesia for Caesarean Section in South-Eastern Nigeria. Journal of Obstetrics \& Gynaecology, 29, 392-395. http://dx.doi.org/10.1080/01443610902932390

[22] Riley, E.T., Cohen, S.E., Macario, A., et al. (1995) Spinal versus Epidural Anesthesia for Cesarean Section: A Comparison of Time Efficiency, Costs, Charges and Complications. Anesthesia and Analgesia, 80, 709-712.

[23] Desalu, I. and Afolabi, B.B. (2007) Urgency of Surgery and Presence of Maternal Disease Influence the Choice of Anaesthesia for Caesarean Section at LUTH. The Nigerian Postgraduate Medical Journal, 14, 114-117. 
Scientific Research Publishing (SCIRP) is one of the largest Open Access journal publishers. It is currently publishing more than 200 open access, online, peer-reviewed journals covering a wide range of academic disciplines. SCIRP serves the worldwide academic communities and contributes to the progress and application of science with its publication.

Other selected journals from SCIRP are listed as below. Submit your manuscript to us via either submit@scirp.org or Online Submission Portal.
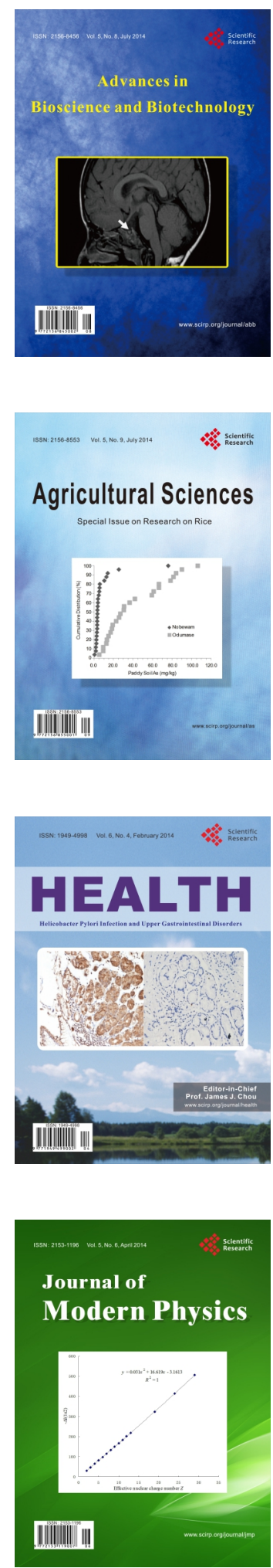
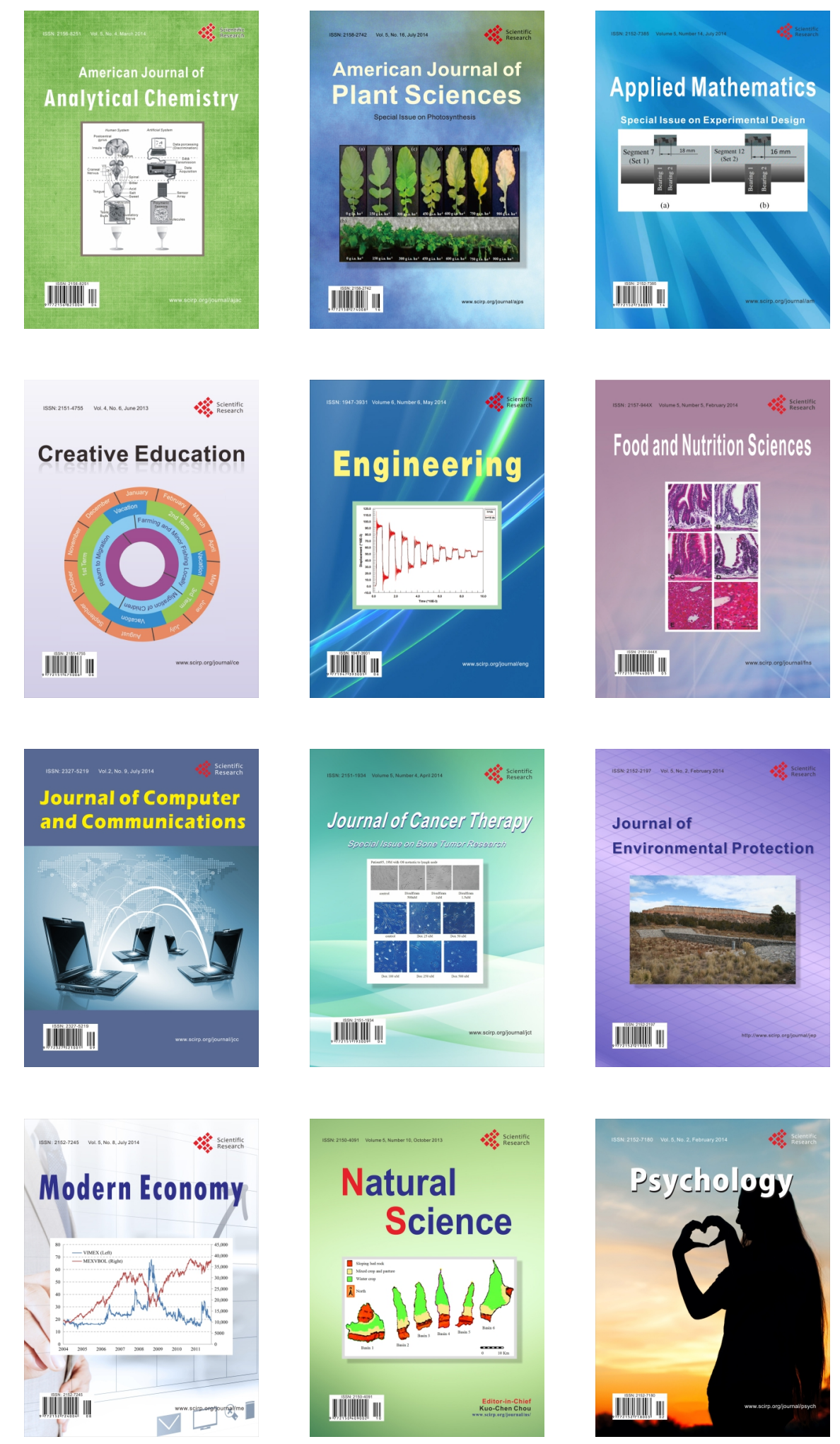